\title{
Fertilidade do solo e absorção de nutrientes em cana-de-açúcar fertilizada com torta de filtro ${ }^{1}$
}

\author{
Agenor B. de Almeida Júnior ${ }^{2}$, Clístenes W. A. do Nascimento ${ }^{2}$, \\ Márcio F. Sobral ${ }^{2}$, Fernando B. V. da Silva ${ }^{2} \&$ Wellington A. Gomes ${ }^{2}$
}

RESU M 0

A utilização dos resíduos orgânicos assume relevante importância nos dias atuais, devido à sua potencialidade de reduzir custos de produção e minimizar impactos ambientais. 0 trabalho foi desenvolvido objetivando-se avaliar o efeito de diferentes doses de fertilizantes orgânico e mineral na cultura da cana-de-açúcar e nos atributos químicos do solo. 0 experimento foi conduzido em casa de vegetação em delineamento de blocos casualizados e tratamentos distribuídos em esquema fatorial $(5 \mathrm{x}$ 3), sendo cinco doses de torta de filtro $(0 ; 9,25 ; 18,5 ; 27,75$ e $35 \mathrm{~g}$ vaso-1) e três níveis de fertilizante mineral (0; 50 e $100 \%$ da dose recomendada), com três repetições, com uma planta por parcela. A aplicação de torta de filtro promoveu melhoria na fertilidade do solo em virtude de aumentar os teores de macro e micronutrientes no solo e reduzir os teores de Al. A torta de filtro promove correção da acidez do solo enquanto os fertilizantes minerais promoveram sua acidificação. A cana-de-açúcar respondeu à adubação com torta de filtro, a qual aumentou o acúmulo de fósforo, potássio e cobre na parte aérea. Recomenda-se o uso de $9,25 \mathrm{~g}$ de torta de filtro associada a $50 \%$ da adubação mineral, como maneira de maximizar o efeito sobre a produtividade e reduzir custos com fertilizantes minerais.

Palavras-chave: Saccharum officinarum L, adubação fosfatada, adubação orgânica, acidez

\section{Soil fertility and uptake of nutrients by sugarcane fertilized with filter cake}

\begin{abstract}
A B ST RACT
The use of organic wastes plays an important role in agriculture due to its potential for reducing cost of production and minimize environmental impacts. The work was carried out to evaluate the effect of mineral fertilizer and filter cake doses on sugarcane yield and soil chemical characteristics. The experiment was conducted in greenhouse in a randomized block design arranged in a factorial outline with five doses of filter cake $\left(0 ; 9.25 ; 18.5 ; 27.75\right.$ e $\left.35 \mathrm{~g} \mathrm{pot}^{-1}\right)$, three levels of mineral fertilizer $(0 ; 50$ e $100 \%$ of the recommended dose) and three replicates with one plant per plot. The results showed that filter cake addition favored soil fertility, increasing the contents of both macro and micronutrients and decreasing Al concentration. Filter cake increased $\mathrm{pH}$ while mineral fertilizer acidified the soil. Sugarcane plants responded to filter cake application by increasing the uptake of phosphorus, potassium and copper. The use of $9.25 \mathrm{~g}$ of filter cake associated with $50 \%$ of the mineral fertilization usually recommended is sufficient in order to increase sugarcane yield while reducing costs with mineral fertilizers.
\end{abstract}

Key words: Saccharum officinarum L, phosphorus fertilization, organic fertilization, acidity 


\section{INTRODUÇÃO}

O cultivo da cana-de-açúcar tem chamado a atenção do mundo, principalmente diante do impacto ambiental causado pela utilização de combustíveis fósseis, desde a revolução industrial e pelo fato do álcool da cana-de-açúcar ser uma das biotecnologias mais acessíveis para a geração de energia limpa em substituição ao petróleo, caracterizando-se como a segunda cultura mais importante para o agronegócio brasileiro (Vitti \& Mazza, 2002).

A agroindústria canavieira, por sua vez, é produtora de enormes quantidades de resíduos orgânicos os quais têm sido alvo, nos últimos anos e em virtude dos altos custos com fertilizantes minerais, de especial atenção na agricultura, como agente condicionador das propriedades físicas, químicas e biológicas do solo. Dentre esses resíduos pode-se destacar a torta de filtro, resíduo composto da mistura de bagaço moído da cana e lodo da decantação, proveniente do processo do tratamento e clarificação do caldo da cana-de-açúcar (Cortez et al., 1992).

No Brasil a importância da torta de filtro resulta não só do grande volume gerado (30 a $40 \mathrm{~kg}$ por tonelada de cana moída), mas também do percentual considerável de matéria orgânica e de elementos essenciais às plantas podendo substituir, ainda que parcialmente, os fertilizantes minerais (Nunes Júnior, 2008; Santos et al., 2011).

A composição química da torta de filtro é variável em função da variedade e da maturação da cana, tipo de solo, processo de clarificação do caldo e outros. Na fração mineral, integrando a composição química da torta de filtro, o P é o elemento predominante (Almeida Júnior, 2010). Apesar de seu pequeno requerimento pelos vegetais, é um dos nutrientes aplicados em maiores quantidades nos solos brasileiros em face à sua baixa disponibilidade natural e à afinidade com a fração mineral por este elemento (Bastos et al., 2008; Korndörfer \& Melo, 2009). Graças a essas características a torta de filtro pode desempenhar papel fundamental na produção agrícola, na manutenção da fertilidade do solo e como condicionadora de solos (Rosseto et al., 2008).

Dentre os efeitos da torta de filtro sobre as propriedades químicas do solo, o aumento sobre disponibilidade de nitrogênio, fósforo e cálcio, a CTC e a diminuição nos teores de Al trocável, merecem destaque (Korndorfer \& Anderson, 1997).
Silva \& Ribeiro (1995) observaram, avaliando a influência do cultivo contínuo de cana-de-açúcar por até 25 anos nas propriedades químicas de solos argilosos, que o manejo adequado dos solos com a adição de vinhaça e torta de filtro, pode melhorar as características químicas dos solos cultivados em relação ao solo nativo, não constatando redução no carbono orgânico nas áreas de cultivo.

O aumento na produtividade da cultura da cana-de-açúcar advindo do uso da torta de filtro tem sido relatado por Donzelli \& Penatti (1997); Santos et al. (2010).

Trabalhos sobre o uso da torta de filtro na cultura da canade-açúcar em solos da região de Pernambuco são incipientes; desta forma, o presente estudo objetivou avaliar os efeitos da aplicação de doses de torta de filtro e de fertilizante mineral sobre os atributos químicas do solo e determinar a melhor combinação dessas fontes na produção de massa seca de planta de cana-de-açúcar em condições controladas.

\section{Material E MÉTODOS}

O experimento foi conduzido em casa de vegetação no Departamento de Agronomia da Universidade Federal Rural de Pernambuco (UFRPE), Recife, PE, localizado nas coordenadas $8^{\circ} 00^{\prime} 59^{\prime \prime} \mathrm{S}$ e $34^{\circ} 56^{\prime} 40^{\prime \prime} \mathrm{W}$ com $28 \mathrm{~m}$ de altitude. O clima da região, segundo classificação de Köppen, é do tipo As', ou seja, quente e úmido. A torta de filtro utilizada no ensaio foi produzida na usina Santa Tereza, localizada em Goiana, PE; depois de seco este material foi destorroado e passado em peneiras de $2 \mathrm{~mm}$ de abertura de malha, posteriormente, submetido a digestão sulfúrica, para determinação do $\mathrm{N}$ total; digestão nítricoperclórica para determinação dos elementos $\mathrm{P}, \mathrm{K}, \mathrm{Ca}, \mathrm{Mg}, \mathrm{Cu}$, Fe, Zn e Mn (EMBRAPA, 1999) com medida do pH em água (EMBRAPA, 1997) e combustão em mufla, para determinação do conteúdo de matéria orgânica (EMBRAPA, 1999). Os resultados dessas análises estão apresentados na Tabela 1 .

O solo utilizado neste ensaio foi coletado da camada de 00,2 m de profundidade, de um Espodossolo, textura areia franca, coletado na usina Santa Tereza, no município de Goiana, PE. As amostras de solo foram caracterizadas química e fisicamente (Tabela 2) de acordo com a metodologia preconizada pela EMBRAPA(1997).

O delineamento experimental adotado foi em blocos casualizados e os tratamentos distribuídos em esquema fatorial

Tabela 1. Características químicas e teor de umidade da torta de filtro utilizada no experimento

\begin{tabular}{|c|c|c|c|c|c|c|c|c|c|c|c|c|c|}
\hline $\mathrm{pH}$ & $\mathrm{N}$ & $\mathbf{P}$ & K & $\mathrm{Na}$ & $\mathrm{Ca}$ & $\mathrm{Mg}$ & $\mathrm{Cu}$ & $\mathrm{Fe}$ & $\mathrm{Zn}$ & $\mathrm{Mn}$ & $\mathrm{C}$ & $\mathrm{C} / \mathrm{N}$ & Umidade \\
\hline $\mathrm{H}_{2} \mathrm{O}(1: 2,5)$ & \multicolumn{10}{|c|}{ 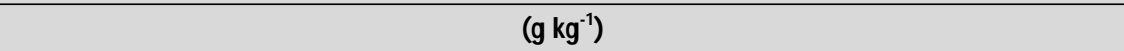 } & \multicolumn{3}{|c|}{ (\%) } \\
\hline 6,8 & 14,2 & 17,3 & 1,45 & 0,34 & 25,3 & 3,4 & $\mathrm{Nd}$ & 7,45 & 0,2 & 1,06 & 44,5 & 31,3 & 59,7 \\
\hline
\end{tabular}

$\mathrm{N}$ - digestão sulfúrica; $\mathrm{P}, \mathrm{K}, \mathrm{Na}, \mathrm{Cu}, \mathrm{Fe}, \mathrm{Zn}$ e $\mathrm{Mn}$ - digestão nítrica-perclórica; MO - matéria orgânica (método da mufla). Laboratório de Fertilidade do solo, UFRPE, Recife

Tabela 2. Atributos químicos e físicos do solo anteriores à instalação do ensaio

\begin{tabular}{|c|c|c|c|c|c|c|c|c|c|c|c|c|c|c|c|c|c|}
\hline \multirow{2}{*}{$\begin{array}{c}\mathrm{pH}^{(1)} \\
(1: 2,5)\end{array}$} & $\mathrm{H}+\mathrm{Al}^{(2)}$ & $\mathrm{Al}^{(3)}$ & $\mathrm{Ca}{ }^{(3)}$ & $\mathrm{Mg}^{(3)}$ & $K^{(4)}$ & \multirow{2}{*}{$\begin{array}{c}P^{(4)} \\
\mathrm{mg} \mathrm{dm}^{-3}\end{array}$} & $N^{(5)}$ & $\mathrm{C} / \mathrm{N}$ & $\mathrm{MO}^{(6)}$ & $\mathrm{Cu}^{(4)}$ & $\mathrm{Fe}^{(4)}$ & $\mathrm{Zn}^{(4)}$ & $M n^{(4)}$ & Areia ${ }^{(7)}$ & Silte ${ }^{(7)}$ & Argila ${ }^{(7)}$ & \multirow{2}{*}{$\begin{array}{l}D{ }^{(8)} \\
\mathrm{g} \mathrm{cm}^{-3}\end{array}$} \\
\hline & \multicolumn{5}{|c|}{$\mathrm{cmol}_{\mathrm{c}} \mathrm{dm}^{-3}$} & & \multicolumn{3}{|c|}{$\mathrm{g} \mathrm{kg}^{-1}$} & \multicolumn{4}{|c|}{$\mathrm{mg} \mathrm{kg}^{-1}$} & \multicolumn{3}{|c|}{$\mathrm{g} \mathrm{kg}^{-1}$} & \\
\hline 6,50 & 3,81 & 0,05 & 2,22 & 0,62 & 0,21 & 9,00 & 0,6 & $12 / 1$ & 12,3 & $\mathrm{Nd}$ & 70,88 & 1,04 & 0,83 & 860 & 100 & 40 & 1,53 \\
\hline
\end{tabular}

(1) Extrator água (1:2,5) (EMBRAPA, 1997); (2) Extrator acetato de cálcio a pH 7,0 (EMBRAPA, 1997); ${ }^{(3)}$ Extrator KCI 1 mol L-1 (EMBRAPA, 1997); (4) Extrator Mehlich-1(EMBRAPA, 1997); (5) Tedesco (1995);

${ }^{\left({ }^{6}\right)} \mathrm{MO}$ - matéria orgânica dicromato de potássio (EMBRAPA, 1997). ${ }^{(7)}$ Método da pipeta (EMBRAPA, 1997); ${ }^{(8)}$ Ds - densidade do solo pelo método da proveta (EMBRAPA, 1997) 
$5 \times 3$, com três repetições, com uma planta por parcela. O primeiro fator constitui-se de cinco doses de torta de filtro $(0 ; 9,25 ; 18,5$; 27,75 e $37 \mathrm{~g} \mathrm{~kg}^{-1}$ de solo) e correspondeu a $0 ; 28,3 ; 56,6 ; 84,9$ e $113,2 \mathrm{Mg} \mathrm{ha}^{-1}$, respectivamente; o segundo fator se refere a três níveis de adubação mineral ( 0,50 e $100 \%$ da recomendação). As doses de torta de filtro foram denominadas $\mathrm{AO}_{0}, \mathrm{AO}_{1}, \mathrm{AO}_{2}$, $\mathrm{AO}_{3}$ e $\mathrm{AO}_{4}$, respectivamente enquanto os níveis de adubo mineral receberam a seguinte denominação: AM0, AM1 e AM2, respectivamente.

A fertilização mineral completa ( $100 \%$ da adubação mineral), de acordo com Nascimento et al. (2006), foi realizada com 350 $\mathrm{g} \mathrm{kg}^{-1} \mathrm{de} \mathrm{N}\left(119 \mathrm{~g} \mathrm{~kg}^{-1} \mathrm{de}\left(\mathrm{NH}_{4}\right)_{2} \mathrm{SO}_{4}+231 \mathrm{~g} \mathrm{~kg}^{-1}+\left(\mathrm{NH}_{4}\right)_{2} \mathrm{HPO}_{4}\right)$, $424 \mathrm{~g} \mathrm{~kg}^{-1} \mathrm{de} \mathrm{P}\left(340 \mathrm{~g} \mathrm{~kg}^{-1} \mathrm{de}\left(\mathrm{NH}_{4}\right)_{2} \mathrm{HPO}_{4}+84 \mathrm{~g} \mathrm{~kg}^{-1} \mathrm{de} \mathrm{K}_{2} \mathrm{HPO}_{4}\right)$ e $212 \mathrm{~g} \mathrm{~kg}^{-1} \mathrm{de} \mathrm{K}_{2} \mathrm{HPO}_{4}$ e os micronutrientes $\mathrm{Cu}\left(\mathrm{CuSO}_{4}\right), \mathrm{Fe}$ $\left(\mathrm{FeSO}_{4} .7 \mathrm{H}_{2} \mathrm{O}\right), \mathrm{Zn}\left(\mathrm{ZnSO}_{4} \cdot 7 \mathrm{H}_{2} \mathrm{O}\right), \mathrm{Mn}\left(\mathrm{MnCl} .4 \mathrm{H}_{2} \mathrm{O}\right), \mathrm{B}\left(\mathrm{H}_{3} \mathrm{BO}_{3}\right)$ e $\mathrm{Mo}\left(\mathrm{Na}_{2} \mathrm{MoO}_{4} \cdot 2 \mathrm{H}_{2} \mathrm{O}\right)$ foram aplicados nas concentrações de 2,$1 ; 2,8 ; 5,7 ; 5,7 ; 1,4$ e $0,3 \mathrm{mg} \mathrm{kg}^{-1}$, respectivamente.

O solo foi secado ao ar, destorroado e passado em peneira de $2 \mathrm{~mm}$ de abertura de malha; posteriormente, realizaram-se a incorporação e a homogeneização dos fertilizantes ao solo (12 $\mathrm{kg}$ ) em vasos plásticos com volume de 10L; após a adição do fertilizante orgânico e mineral as amostras de solo permaneceram incubadas durante 17 dias realizando-se, depois da incubação, o plantio de uma gema de cana-de-açúcar, da variedade RB92579; durante o ensaio o solo foi mantido a $70 \%$ da capacidade de campo, mediante pesagem e irrigações diárias para complementação da água perdida por evapotranspiração.

Aos 90 dias, por ocasião da colheita, quantificou-se a massa seca da parte aérea (MSPA); para determinação da MSPA o tecido vegetal foi secado em estufa de circulação de ar forçada, a $65^{\circ} \mathrm{C}$, por $72 \mathrm{~h}$, e posteriormente pesado; com vista à secagem, as amostras da parte aérea foram moídas em moinho tipo Willey e realizadas as seguintes análises: $\mathrm{N}, \mathrm{P}, \mathrm{K}, \mathrm{Ca}, \mathrm{Mg}, \mathrm{Cu}, \mathrm{Fe}, \mathrm{Zn}$ e Mn (EMBRAPA, 1999); o N total foi extraído por digestão sulfúrica (método Kjeldahl), enquanto os demais elementos foram digeridos em solução nítrico-perclórica na proporção de $4: 1$.

Aos noventa dias de cultivo o solo de cada tratamento foi coletado, secado ao ar, destorroado e passado em peneira de 2 $\mathrm{mm}$ de abertura de malha; nas amostras foram determinadas as seguintes características: $\mathrm{pH}$ em água $(1: 2,5), \mathrm{Al}^{3+}, \mathrm{N}, \mathrm{P}, \mathrm{K}^{+}$, $\mathrm{Ca}^{2+}, \mathrm{Mg}^{2+}, \mathrm{MO}$ (método Walkley-Black), $\mathrm{Cu}, \mathrm{Fe}, \mathrm{Mn}$ e $\mathrm{Zn}$, conforme metodologia descrita pela EMBRAPA (1999), cujos resultados foram submetidos à análise de variância (ANOVA), com as médias comparadas pelo teste de Tukey a 5\% de probabilidade; além disso, foram realizadas análises de regressão e ajuste de equações para os atributos químicos do solo em função das doses de torta de filtro e fertilizante mineral, utilizando-se o software SAEG versão 9.1.

\section{RESULTADOS E DISCUSSÃO}

\section{Produção de massa seca de plantas de cana-de-açúcar}

Ocorreram respostas significativas $(\mathrm{p}<0,01)$ pelo teste $\mathrm{F}$ da interação entre adubação orgânica e mineral, para a produção de massa seca da parte aérea (MSPA) (Tabela 3); no desdobramento das interações não se verificaram ajustes nos modelos de regressão para as médias da MSPA, exceto na ausência da adubação mineral $\left(\mathrm{AM}_{0}\right)$, a qual se ajustou ao modelo $\hat{y}=22,30+11,96 * x^{0,5}-1,66 * x\left(R^{2}=0,96 *\right)$; por meio deste modelo verificou-se que a máxima eficiência física foi obtida na dose de $1,49 \mathrm{~g} \mathrm{~kg}^{-1}$ de solo (4,6 $\mathrm{Mg} \mathrm{ha}^{-1}$ de base seca) obtendo-se, assim, uma produção máxima de 24,76 g.

Tabela 3. Análise de variância para massa seca da parte aérea (M SPA) de plantas de cana-de-açúcar em função de diferentes doses de torta de filtro e fertilizante natural

\begin{tabular}{ccc}
\hline Fonte de variação & GL & Valor F \\
\cline { 3 - 3 } & & MSPA \\
Torta de filtro (T) & 4 & $4,88^{* *}$ \\
Fertilizante mineral (M) & 2 & $51,66^{* * *}$ \\
T x M & 8 & $3,54^{* *}$ \\
Repetição & 2 & $7,00^{* *}$ \\
\hline CV (\%) & & 11,4 \\
Média geral & 47,9 \\
\hline CV $=$ coeficiente de varianã *** $e^{* *}$, &
\end{tabular}

$\mathrm{CV}=$ coeficiente de variação; ${ }^{* * *} \mathrm{e}^{* *}$, respectivamente: significante a 0,001 e 0,01 de probabilidade

Os resultados indicam efeito positivo do uso da torta de filtro na ausência da adubação mineral sobre a MSPA da canade-açúcar, observando-se incremento de 51,5 \% na produção, na dose 9,25 $\mathrm{g} \mathrm{kg}^{-1}$, em relação à testemunha (Tabela 4).

Tabela 4. Produção de massa seca ( $g$ vaso-1) na parte aérea (MSPA) de plantas de cana-de-açúcar em função de diferentes níveis de torta de fil tro e fertilizante mineral

\begin{tabular}{cccc}
\hline Torta de & \multicolumn{3}{c}{ Fertilizante mineral (\%) } \\
\cline { 2 - 4 } filtro & $\mathbf{0}$ & $\mathbf{5 0}$ & $\mathbf{1 0 0}$ \\
\cline { 2 - 4 }$\left(\mathbf{g ~ k g}^{-1}\right)$ & \multicolumn{3}{c}{ MSPA $\left(\mathbf{g ~ v a s 0}^{-\mathbf{1}}\right)$} \\
0 & $21,95 \mathrm{bB}$ & $51,33 \mathrm{aA}$ & $53,54 \mathrm{aA}$ \\
9,25 & $45,30 \mathrm{aB}$ & $57,04 \mathrm{aA}$ & $50,71 \mathrm{aAB}$ \\
18,50 & $41,55 \mathrm{aA}$ & $52,57 \mathrm{aA}$ & $50,90 \mathrm{aA}$ \\
27,75 & $37,16 \mathrm{aB}$ & $47,71 \mathrm{aA}$ & $50,15 \mathrm{aA}$ \\
37 & $35,01 \mathrm{aB}$ & $60,90 \mathrm{aA}$ & $60,70 \mathrm{aA}$ \\
\hline
\end{tabular}

Letras minúsculas e distintas na coluna e letras maiúsculas distintas na linha diferem entre si pelo teste Tukey a $5 \%$ de probabilidade

Santos et al. (2010) também constataram, trabalhando com cana-de-açúcar em condições de campo, resposta da cultura à adubação com torta de filtro ao solo. $\mathrm{O}$ beneficio da torta de filtro também foi relatado por Fravet et al. (2010), em estudo de campo com cana-soca, ao verificarem que o uso de $70 \mathrm{t} \mathrm{ha}^{-1} \mathrm{de}$ torta de filtro fresca proporcionou maior produção de colmos de cana-de-açúcar. Segundo Rossetto et al. (2008), o uso da torta de filtro em canaviais, eleva a produtividade da cultura por fornecer matéria orgânica, fósforo e cálcio, entre outros nutrientes.

De acordo com os resultados obtidos neste estudo, a canade-açúcar respondeu satisfatoriamente à adubação orgânica, o que pode ter ocorrido devido à mineralização da torta de filtro, com consequente disponibilização de nutrientes ao solo, propiciando ganhos na biomassa da cultura; neste sentido, Matsuoka et al. (2002) afirmam que a produção de cana orgânica é viável, pois se conseguem produtividades agrícolas similares às obtidas com adubação mineral. Por outro lado e de acordo com Nardin (2007), o uso de torta de filtro em Argiloso não foi 
suficiente para que ocorressem diferenças significativas na produtividade da cana-de-açúcar, independentemente da forma de aplicação.

Embora não se tenha verificado ajustes nos modelos de regressão nos níveis de fertilizante mineral, os resultados evidenciam que, embora a torta de filtro seja um forte aliado no aumento da produção da MSPA da cana-de-açúcar, sua combinação com $50 \%$ da fonte mineral deve ser recomendada por elevar a produção da MSPA da cana-de-açúcar (Tabela 4); resultados similares obtiveram Donzelli \& Penatti (1997), trabalhando em condições de campo com a variedade SP801842 em um Latossolo Roxo Ácrico; esses autores verificaram, por sua vez, que o melhor retorno econômico ocorreu quando se aplicaram $21 \mathrm{t} \mathrm{ha}^{-1}$ de torta no sulco de plantio, juntamente com a complementação mineral de $30 \mathrm{~kg} \mathrm{ha}^{-1}$ de $\mathrm{Ne} 140 \mathrm{~kg} \mathrm{ha}^{-1}$ de $\mathrm{K} 2 \mathrm{O}$.

Vários autores enfatizam a importância de doses combinadas de matéria orgânica e fertilizantes minerais no rendimento das culturas. Oliveira et al. (2002), estudando o efeito da adubação mineral e orgânica sobre a produção de biomassa de Cymbopogon citratus (DC) Stapf, com aplicação de fertilizante orgânico $\left(2 \mathrm{~kg} \mathrm{cova}^{-1}\right)$, fertilizante mineral (N P K 4-14-8) com 37 $\mathrm{g} \mathrm{cova}^{-1}$, fertilizante mineral + orgânico e a testemunha (sem fertilizante), observaram que as melhores produções foram obtidas nos tratamentos adubação orgânica + mineral e adubação orgânica. Lima et al. (2001), ao avaliarem o crescimento de mudas de cajueiro submetidos à adubação orgânica e mineral, também verificaram acréscimos nos parâmetros de crescimento da cultura com a obtenção da combinação de doses de matéria orgânica e fertilizantes minerais.

\section{Alterações na fertilidade do solo em função da adubação orgâ- nica e mineral}

Ocorreram diferenças significativas $(\mathrm{p}<0,05)$ pelo teste $\mathrm{F}$, da interação fertilizante orgânico e mineral para quase todas as variáveis estudadas, exceto para o $\mathrm{N}$ total, $\mathrm{Cu}, \mathrm{Fe}$ e Zn (Tabela 5).

Os valores de $\mathrm{pH}$ do solo apresentaram aumentos lineares e significativos com o aumento da dose de torta de filtro aplicada, em ambos os níveis de adubação mineral (Tabelas 6), evidenciando leve alcalinização do solo como consequência do incremento das doses de torta de filtro; resultados semelhantes foram obtidos para os demais níveis de adubação mineral, mostrando o efeito alcalinizante do resíduo; este efeito ocorreu, possivelmente, em virtude da alcalinidade do material utilizado visto que durante o processo de clarificação do caldo é adicionado o cal $\left[\mathrm{Ca}(\mathrm{OH})_{2}\right]$ que auxilia na floculação das impurezas. Desta forma, a torta de filtro se mostra como alternativa promissora na correção da acidez do solo mas se tornam imprescindíveis estudos a fim de se verificar a ação corretiva da acidez do solo, ao longo do tempo de cultivo; por outro lado, a importância da adubação orgânica na correção da acidez do solo também tem sido relatada por vários autores (Almeida, 2003; Amaral et al., 2000; Mieyazawa et al., 1993). Apesar disto, a adubação mineral reduziu significativamente ( $\mathrm{p}<0,01)$ os valores de $\mathrm{pH}$ do solo, tendo esta redução atingido o patamar de 1,39 e 1,81 unidades para os níveis de 50 e 100\%, respectivamente, fato devido, sem dúvida, à utilização do sulfato de amônio (Primavesi et al., 2005; Purquerio \& Cecílio Filho, 2005; Souza et al., 2006; Souza \& Silva, 2009; Teixeira et al., 2001).

A torta de filtro reduziu significativamente $(\mathrm{p}<0,01)$ os teores de Al trocável no solo (Tabela 5), consequência do efeito corretivo da torta de filtro e da complexação do Al por ácidos orgânicos existentes na torta de filtro. Segundo vários autores (Mendonça et al., 2006; Simas et al., 2005; van Hees et al., 2000), diversos compostos orgânicos, especialmente ácidos orgânicos, apresentam grande afinidade e capacidade de formar complexos estáveis com $\mathrm{Al}^{+3}$ diminuindo sua atividade na solução do solo enquanto a adubação mineral promoveu aumentos significativos nos valores do $\mathrm{Al}^{+3}$ (Tabela 6), corroborando com os resultados obtidos por Perin et al. (2003); portanto, o uso da torta de filtro pode ser uma alternativa promissora em virtude de reduzir à acidificação dos solos e a toxidez de $\mathrm{Al}$ às plantas.

Houve aumentos lineares e significativos $(\mathrm{p}<0,05)$ nos teores de $\mathrm{N}$ após a adição da torta de filtro e fertilizante mineral (Tabela 6); na ausência da adubação mineral os teores de $\mathrm{N}$ do solo variaram de 0,56 a $1,03 \mathrm{~g} \mathrm{~kg}^{-1}$, tendo a dose $18,5 \mathrm{~g}$ obtido

Tabela 5. Análise de variância para os atributos químicos do solo a doses crescentes de torta de filtro e fertilizante mineral

\begin{tabular}{|c|c|c|c|c|c|c|c|}
\hline \multirow{2}{*}{ Fonte de variação } & \multirow{2}{*}{ GL } & \multicolumn{6}{|c|}{ Valor F } \\
\hline & & $\mathrm{pH}$ & Al & $\mathbf{N}$ & $\mathbf{P}$ & $\mathbf{K}$ & $\mathrm{Ca}$ \\
\hline Torta de filtro (T) & 4 & $100,51 * * *$ & $55,52 * * *$ & $39,41 * * *$ & $857,69 * * *$ & $44,55 * * *$ & $168,98^{* * *}$ \\
\hline Fertilizante mineral (M) & 2 & $1763,50 * * *$ & $553,72 * * *$ & $11,65^{* * *}$ & $1064,06 * * *$ & $838,86 * * *$ & $1,23^{\mathrm{ns}}$ \\
\hline$T \times M$ & 8 & $4,69 * *$ & $9,26 * * *$ & $0,49^{\mathrm{ns}}$ & $2,30 *$ & $3,08 *$ & $4,38 * *$ \\
\hline Repetição & 2 & $1,78^{\mathrm{ns}}$ & $1,60^{\mathrm{ns}}$ & $0,74^{\mathrm{ns}}$ & $0,25^{\mathrm{ns}}$ & $2,26^{\mathrm{ns}}$ & $0,28^{\mathrm{ns}}$ \\
\hline CV $(\%)$ & & 1,59 & 14,07 & 8,98 & 4,29 & 9,93 & 3,76 \\
\hline Média geral & & 5,49 & 0,25 & 0,88 & 56,16 & 0,25 & 4,34 \\
\hline \multirow{2}{*}{ Fonte de variação } & \multirow{2}{*}{ GL } & \multicolumn{6}{|c|}{ Valor $F$} \\
\hline & & Mg & $\mathrm{Fe}$ & $\mathrm{Zn}$ & $\mathrm{Cu}$ & Mn & MOS \\
\hline Torta de filtro (T) & 4 & $109,59 * * *$ & $30,68 * * *$ & $265,37 * * *$ & $300,46 * * *$ & $707,38 * * *$ & $55,65 * * *$ \\
\hline Fertilizante mineral (M) & 2 & $5,10 *$ & $10,35 * * *$ & $460,14 * * *$ & $176,37 * * *$ & $48,00 * * *$ & $2,12^{\text {ns }}$ \\
\hline$T \times M$ & 8 & $4,36 * * *$ & $2,13^{\text {ns }}$ & 0,59 ns & $0,86^{\mathrm{ns}}$ & $4,24 * *$ & $0,72^{\mathrm{ns}}$ \\
\hline Repetição & 2 & $0,08^{\mathrm{ns}}$ & $3,26^{\mathrm{ns}}$ & $0,52^{\mathrm{ns}}$ & $2,73^{\mathrm{ns}}$ & $0,12^{\mathrm{ns}}$ & $0,32^{\mathrm{ns}}$ \\
\hline CV (\%) & & 10,75 & 7,69 & 5,56 & 6,12 & 5,50 & 7,96 \\
\hline Média geral & & 2,19 & 101,60 & 9,73 & 2,66 & 40,37 & 19,71 \\
\hline
\end{tabular}

CV - coeficiente de variação; *, ** e *** - significativos a 5\%, 1\% e 0,1\% de probabilidade, respectivamente; ns - não significativo 
Tabela 6. Atributos químicos do solo submetido a doses crescentes de torta de filtro $\left(\mathrm{g} \mathrm{kg}^{-1}\right)$, com suas respectivas equações de regressão e coeficientes de determinação $\left(R^{2}\right)$, nos diferentes níveis de fertilizante mineral

\begin{tabular}{|c|c|c|c|c|c|c|c|}
\hline \multirow{2}{*}{$\begin{array}{l}\text { Fertilizante } \\
\text { mineral }\end{array}$} & \multicolumn{5}{|c|}{ Torta de filtro $\left(\mathrm{g} \mathrm{kg}^{-1}\right)$} & \multirow{2}{*}{ Equação de regressão } & \multirow{2}{*}{$\mathbf{R}^{2}$} \\
\hline & 0 & 9,25 & 18,5 & 27,75 & 37 & & \\
\hline $\begin{array}{c}0 \\
50 \\
100\end{array}$ & $\begin{array}{l}6,23 a \\
4,56 b \\
4,43 b\end{array}$ & $\begin{array}{l}6,36 a \\
5,06 b \\
4,63 c\end{array}$ & $\begin{array}{l}6,60 \mathrm{a} \\
5,20 \mathrm{~b} \\
4,80 \mathrm{c}\end{array}$ & $\begin{array}{l}\text { pH (ág } \\
6,80 \mathrm{a} \\
5,40 \mathrm{~b} \\
4,87 \mathrm{c}\end{array}$ & $\begin{array}{l}6,80 a \\
5,63 b \\
5,03 c\end{array}$ & $\begin{array}{l}\hat{Y}=6,24+0,017^{* *} x \\
\hat{Y}=4,67+0,026^{* * x} x \\
\hat{Y}=4,46+0,015^{* *} x\end{array}$ & $\begin{array}{l}0,94 * * \\
0,95 * * \\
0,97 * *\end{array}$ \\
\hline $\begin{array}{c}0 \\
50 \\
100 \\
\end{array}$ & $\begin{array}{l}0,06 \mathrm{c} \\
0,40 \mathrm{~b} \\
0,66 \mathrm{a}\end{array}$ & $\begin{array}{l}0,06 c \\
0,33 b \\
0,53 a\end{array}$ & $\begin{array}{l}0,00 \mathrm{c} \\
0,23 \mathrm{~b} \\
0,46 \mathrm{a}\end{array}$ & $\begin{array}{c}\text { Al (cmolc } \\
0,00 \mathrm{c} \\
0,21 \mathrm{~b} \\
0,35 \mathrm{a} \\
\end{array}$ & $\begin{array}{l}0,00 \mathrm{~b} \\
0,21 \mathrm{a} \\
0,28 \mathrm{a} \\
\end{array}$ & $\begin{array}{l}\hat{Y}=0,06-0,0019 * x \\
\hat{Y}=0,37-0,005 * * x \\
\hat{Y}=0,64-0,01 * * x\end{array}$ & $\begin{array}{l}0,75^{*} \\
0,88 * \\
0,99 * * \\
\end{array}$ \\
\hline $\begin{array}{c}0 \\
50 \\
100\end{array}$ & $\begin{array}{l}0,56 \mathrm{~b} \\
0,70 \mathrm{ab} \\
0,75 \mathrm{a}\end{array}$ & $\begin{array}{l}0,70 a \\
0,79 a \\
0,79 a\end{array}$ & $\begin{array}{l}0,88 \mathrm{a} \\
0,93 \mathrm{a} \\
1,02 \mathrm{a}\end{array}$ & $\begin{array}{l}\mathrm{N}(\mathrm{g} \mathrm{k} \\
0,91 \mathrm{a} \\
0,93 \mathrm{a} \\
1,05 \mathrm{a}\end{array}$ & $\begin{array}{l}1,03 a \\
1,05 a \\
1,16 a\end{array}$ & $\begin{array}{l}\hat{Y}=0,58+0,0124^{* *} \mathrm{X} \\
\hat{Y}=0,71+0,0091^{* *} \mathrm{X} \\
\hat{Y}=0,74+0,0117^{* *} \mathrm{X}\end{array}$ & $\begin{array}{l}0,96 * \\
0,95 * * \\
0,94 * *\end{array}$ \\
\hline $\begin{array}{c}0 \\
50 \\
100 \\
\end{array}$ & $\begin{array}{r}24,4 c \\
254,3 \mathrm{~b} \\
466,5 \mathrm{a} \\
\end{array}$ & $\begin{array}{l}205,4 c \\
412,5 b \\
653,5 a \\
\end{array}$ & $\begin{array}{l}393,1 \mathrm{c} \\
567,2 \mathrm{~b} \\
767,1 \mathrm{a} \\
\end{array}$ & $\begin{array}{l}P(m g ~ c \\
517,6 \mathrm{c} \\
733,3 \mathrm{~b} \\
898,0 \mathrm{a} \\
\end{array}$ & $\begin{array}{r}647,0 \mathrm{c} \\
854,9 \mathrm{~b} \\
1029,6 \mathrm{a} \\
\end{array}$ & $\begin{array}{l}\hat{Y}=46,02+16,84^{* * x} \\
\hat{Y}=260,04+16,45^{* *} x \\
\hat{Y}=488,8+14,82^{* * x}\end{array}$ & $\begin{array}{l}0,99 * * \\
0,99 * * \\
0,99 * * \\
\end{array}$ \\
\hline $\begin{array}{c}0 \\
50 \\
100 \\
\end{array}$ & $\begin{array}{l}0,07 \mathrm{~b} \\
0,11 \mathrm{~b} \\
0,41 \mathrm{a}\end{array}$ & $\begin{array}{l}0,07 c \\
0,13 b \\
0,41 a\end{array}$ & $\begin{array}{l}0,08 c \\
0,21 b \\
0,48 a\end{array}$ & $\begin{array}{l}\mathrm{K}(\mathrm{cmolc} \\
0,10 \mathrm{c} \\
0,25 \mathrm{~b} \\
0,48 \mathrm{a} \\
\end{array}$ & $\begin{array}{l}0,17 c \\
0,29 b \\
0,54 a\end{array}$ & $\begin{array}{l}\hat{Y}=0,07+0,021^{n s} x+0,0001 x^{2 *} \\
\hat{Y}=0,09+0,005^{* *} x \\
\hat{Y}=0,46\end{array}$ & $\begin{array}{c}0,97^{*} \\
0,94^{*} \\
\text { NS }\end{array}$ \\
\hline $\begin{array}{c}0 \\
50 \\
100 \\
\end{array}$ & $\begin{array}{l}2,95 \mathrm{~b} \\
3,40 \mathrm{a} \\
3,26 \mathrm{ab}\end{array}$ & $\begin{array}{l}3,88 \mathrm{~b} \\
4,26 \mathrm{a} \\
4,21 \mathrm{a} \\
\end{array}$ & $\begin{array}{l}4,76 a \\
4,66 a \\
4,48 a\end{array}$ & $\begin{array}{c}\text { Ca (cmolc } \\
4,90 \mathrm{a} \\
4,75 \mathrm{a} \\
4,63 \mathrm{a} \\
\end{array}$ & $\begin{array}{l}5,18 \mathrm{a} \\
4,86 \mathrm{a} \\
4,88 \mathrm{a} \\
\end{array}$ & $\begin{array}{l}\hat{Y}=3,23+0,06 * * x \\
\hat{Y}=3,70+0,04 * x \\
\hat{Y}=3,56+0,04 * x\end{array}$ & $\begin{array}{l}0,89 * \\
0,82 * \\
0,85^{*}\end{array}$ \\
\hline $\begin{array}{c}0 \\
50 \\
100 \\
\end{array}$ & $\begin{array}{l}1,73 \mathrm{a} \\
1,75 \mathrm{a} \\
1,25 \mathrm{~b}\end{array}$ & $\begin{array}{l}1,35 \mathrm{~b} \\
1,21 \mathrm{~b} \\
1,86 \mathrm{a}\end{array}$ & $\begin{array}{l}1,71 \mathrm{a} \\
1,75 \mathrm{a} \\
1,85 \mathrm{a}\end{array}$ & $\begin{array}{c}\mathrm{Mg}(\mathrm{cmol} \\
2,43 \mathrm{~b} \\
2,92 \mathrm{a} \\
3,16 \mathrm{a}\end{array}$ & $\begin{array}{l}2,98 c \\
3,48 a \\
3,43 a b\end{array}$ & $\begin{array}{l}\hat{Y}=1,64+0,03^{n s} x+0,002 * x^{2} \\
\hat{Y}=1,18+0,06^{*} x \\
\hat{Y}=1,17+0,04 * x\end{array}$ & $\begin{array}{l}0,95^{*} \\
0,75^{*} \\
0,91^{*}\end{array}$ \\
\hline $\begin{array}{c}0 \\
50 \\
100\end{array}$ & $\begin{array}{l}88,16 a \\
77,23 a \\
86,46 a\end{array}$ & $\begin{array}{r}76,20 \mathrm{~b} \\
85,63 \mathrm{~b} \\
105,30 \mathrm{a}\end{array}$ & $\begin{array}{l}106,23 \mathrm{a} \\
103,56 \mathrm{a} \\
108,53 \mathrm{a}\end{array}$ & $\begin{array}{r}\mathrm{Fe}(\mathrm{mg} \\
107,23 \mathrm{a} \\
111,56 \mathrm{a} \\
116,36 \mathrm{a}\end{array}$ & $\begin{array}{l}110,96 \mathrm{~b} \\
111,26 \mathrm{~b} \\
128,80 \mathrm{a}\end{array}$ & $\begin{array}{l}\hat{Y}=97,85 \\
\hat{Y}=79,05+1,02 * * x \\
\hat{Y}=89,94+1,03 * * x\end{array}$ & $\begin{array}{l}\mathrm{NS} \\
0,91^{*} \\
0,95^{* *}\end{array}$ \\
\hline $\begin{array}{c}0 \\
50 \\
100 \\
\end{array}$ & $\begin{array}{l}2,63 \mathrm{c} \\
5,89 \mathrm{~b} \\
9,32 \mathrm{a} \\
\end{array}$ & $\begin{array}{r}4,71 \mathrm{c} \\
7,77 \mathrm{~b} \\
10,92 \mathrm{a} \\
\end{array}$ & $\begin{array}{r}7,08 \mathrm{c} \\
9,82 \mathrm{~b} \\
12,98 \mathrm{a} \\
\end{array}$ & $\begin{array}{r}\text { Zn }(\mathrm{mg} \\
8,83 \mathrm{c} \\
11,62 \mathrm{~b} \\
14,42 \mathrm{a} \\
\end{array}$ & $\begin{array}{l}10,52 \mathrm{c} \\
13,33 \mathrm{~b} \\
16,09 \mathrm{a} \\
\end{array}$ & $\begin{array}{l}\hat{Y}=2,77+0,21 * * x \\
\hat{Y}=5,94+0,20 * * x \\
\hat{Y}=9,33+0,18^{* * x}\end{array}$ & $\begin{array}{l}0,99 * * \\
0,99 * * \\
0,99 * * \\
\end{array}$ \\
\hline $\begin{array}{c}0 \\
50 \\
100 \\
\end{array}$ & $\begin{array}{l}0,86 \mathrm{c} \\
1,58 \mathrm{~b} \\
2,16 \mathrm{a} \\
\end{array}$ & $\begin{array}{l}1,45 \mathrm{c} \\
2,02 \mathrm{~b} \\
2,62 \mathrm{a} \\
\end{array}$ & $\begin{array}{l}2,01 \mathrm{c} \\
2,69 \mathrm{~b} \\
3,17 \mathrm{a} \\
\end{array}$ & $\begin{array}{l}\mathrm{Cu}(\mathrm{mg} \\
2,66 \mathrm{c} \\
3,17 \mathrm{~b} \\
3,76 \mathrm{a} \\
\end{array}$ & $\begin{array}{l}3,49 c \\
3,94 b \\
4,35 a \\
\end{array}$ & $\begin{array}{l}\hat{Y}=0,80+0,07 * * x \\
\hat{Y}=1,51+0,06 * * x \\
\hat{Y}=2,11+0,06 * * x\end{array}$ & $\begin{array}{l}0,99 * * \\
0,99 * * \\
0,99 * * \\
\end{array}$ \\
\hline $\begin{array}{c}0 \\
50 \\
100 \\
\end{array}$ & $\begin{array}{r}7,11 \mathrm{c} \\
12,59 \mathrm{~b} \\
20,20 \mathrm{a} \\
\end{array}$ & $\begin{array}{l}22,97 \mathrm{~b} \\
26,51 \mathrm{~b} \\
34,09 \mathrm{a} \\
\end{array}$ & $\begin{array}{l}41,71 \mathrm{~b} \\
41,87 \mathrm{~b} \\
49,25 \mathrm{a} \\
\end{array}$ & $\begin{array}{l}M n(m g \\
55,99 a \\
54,89 a \\
56,70 a \\
\end{array}$ & $\begin{array}{l}59,86 a b \\
57,50 a \\
64,33 a \\
\end{array}$ & $\begin{array}{l}\hat{Y}=9,82+1,49 * * x \\
\hat{Y}=15,03+1,27 * * x \\
\hat{Y}=22,74+1,19 * * x\end{array}$ & $\begin{array}{l}0,96 * * \\
0,96 * * \\
0,97 * * \\
\end{array}$ \\
\hline $\begin{array}{c}0 \\
50 \\
100 \\
\end{array}$ & $\begin{array}{l}14,12 \mathrm{a} \\
15,49 \mathrm{a} \\
14,99 \mathrm{a} \\
\end{array}$ & $\begin{array}{l}16,57 \mathrm{a} \\
16,43 \mathrm{a} \\
18,64 \mathrm{a} \\
\end{array}$ & $\begin{array}{l}20,04 \mathrm{a} \\
19,44 \mathrm{a} \\
19,67 \mathrm{a} \\
\end{array}$ & $\begin{array}{l}\text { MOS lg } \\
20,75 a \\
22,79 a \\
22,18 a \\
\end{array}$ & $\begin{array}{l}23,99 a \\
24,69 a \\
25,86 a \\
\end{array}$ & $\begin{array}{l}\hat{Y}=14,31+0,26^{* *} x \\
\hat{Y}=14,82+0,26^{* *} x \\
\hat{Y}=15,21+0,27^{* *} x\end{array}$ & $\begin{array}{l}0,97 * * \\
0,97 * * \\
0,97 * * \\
\end{array}$ \\
\hline
\end{tabular}

Letras minúsculas e distintas na coluna diferem entre si pelo teste Tukey a $5 \%$ de probabilidade; ${ }^{*} \mathrm{e}^{* *}$ - significativos a 5 e $1 \%$ de probabilidade, respectivamente; ns - não significativo

incremento significativo de $36 \%$ nos teores de $\mathrm{N}$ em relação à testemunha, incremento este que se deve, provavelmente, à mineralização do N orgânico.

A aplicação das doses de torta de filtro promoveu incrementos expressivos nos teores de $\mathrm{P}$ dos solos indicando a eficiência do resíduo em suprir $\mathrm{P}$ para o crescimento vegetal (Tabela 6); os resultados corroboram com os obtidos por Nardin (2007) que, ao avaliar o uso de torta de filtro sobre as propriedades químicas de um Argilosso, verificou incrementos significativos nos teores de $\mathrm{P}$ da camada $20-40 \mathrm{~cm}$. O incremento nos teores de $\mathrm{P}$ do solo se deve aos altos teores de $\mathrm{P}$ presentes na composição química da torta de filtro. Além de ser fonte de $\mathrm{P}$ a torta de filtro pode reduzir a adsorção do elemento em solos, graças ao elevado teor de matéria orgânica que poderá fornecer ácidos orgânicos que competem com o fosfato pelos sítios de adsorção, aumentando a disponibilidade do elemento 
(Alves et al., 1999; Costa et al, 1992; Mazur et al., 1983). De acordo com as regressões apresentadas na Tabela 5 o aumento do aporte de torta de filtro ao solo promoveu resposta linear aos teores de $\mathrm{P}$ nos três níveis de fertilizante mineral; entretanto, esses incrementos decresceram em função do aumento da adubação mineral; resultados similares foram encontrados por Cunha et al. (2007).

De acordo com os níveis de fertilidade de solo proposto por Ribeiro et al. (1999), os teores de $\mathrm{P}$ da testemunha $\left(24,4 \mathrm{mg} \mathrm{dm}^{-3}\right)$ foram classificados como nível médio; contudo, a aplicação da adubação orgânica e/ou adubação mineral elevou esses teores, de modo que eles foram classificados como níveis muito bom (>45 mg dm${ }^{-3}$ ) e os resultados obtidos neste estudo corroboram com o potencial da torta de filtro como fonte fosfatada.

A adição de torta de filtro propiciou incrementos significativos ( $p<0,01$ ) nos teores de $\mathrm{K}$ do solo (Tabelas 6). Observou-se que a adição de torta de filtro alterou a fertilidade do solo passando de baixos teores a altos, de acordo com Calvacanti et al. (2008).

Doses crescentes de torta de filtro aumentaram significativamente $(\mathrm{p}<0,05)$ os teores de Ca do solo (Tabela 6); o incremento deste elemento no solo se deve, sem dúvida, à composição química da torta visto que, em grande quantidade, o Ca é resultado da chamada caleação do caldo durante o processo de tratamento do mesmo para a fabricação do açúcar; resultados similares foram obtidos por Korndorfer \& Anderson (1997). De acordo com os níveis de interpretação de fertilidade do solo estabelecida por Alvarez et al. (1999), os valores obtidos na ausência da adubação com torta de filtro se encontram classificados como bons $\left(2,41-4,00 \mathrm{cmol}_{c} \mathrm{dm}^{-3}\right)$; no entanto se observou, ao se aplicar esta fonte orgânica, alteração na classe de fertilidade, passando a muito bom $\left(>4,00 \mathrm{cmol}_{c}\right.$ $\mathrm{dm}^{-3}$ ), exceção para a $\mathrm{AO}_{1} \mathrm{AM}_{0} ; \mathrm{o} \mathrm{Mg}$ apresentou comportamento similar ao Ca porém se constatou ajuste quadrático para $\mathrm{AM}_{0}$ e linear para $\mathrm{AM}_{1}$ e $\mathrm{AM}_{2}$ (Tabela 6).

Não se verificou efeito significativo $(\mathrm{p}<0,05)$ da interação das fontes orgânicas e minerais para os teores de $\mathrm{Fe}$; na ausência da adubação mineral os teores de Fe não se ajustaram aos modelos de regressão e comportamento antagônico foi obtido para os demais níveis de fertilizante mineral, aumentando linearmente em função do aumento das doses de torta de filtro (Tabela 6); por outro lado, o Fe, apesar de ser o metal em maior concentração na torta de filtro (Tabela 1), apresentou aumento relativamente pequeno de disponibilidade no solo indicando encontrar-se na torta de filtro em forma de baixa disponibilidade como, por exemplo, os óxidos de Fe. Oliveira \& Nascimento (2006), estudando as formas de $\mathrm{Mn}$ e Fe no estado de Pernambuco, verificaram que os maiores teores de Fe potencialmente disponível estão ligados à fração da matéria orgânica; os teores de $\mathrm{Fe}$ disponíveis obtidos no presente estudo se encontram dentro da faixa obtida $\left(8,1\right.$ a $\left.317 \mathrm{mg} \mathrm{dm}^{-3}\right)$ por Oliveira \& Nascimento (2006) ao trabalharem com os solos de Referência do Estado de Pernambuco.

Não se verificou efeito significativo $(\mathrm{p}<0,05)$ da interação fertilizante orgânico x mineral, para os teores de $\mathrm{Zn}$ e $\mathrm{Cu}$ presentes no solo; apesar disto, esses elementos aumentaram linearmente em função da aplicação das doses crescentes de torta de filtro, nos três níveis de adubação mineral, incrementos esses menores com o aumento da fonte mineral (Tabela 6), enquanto doses crescentes de torta de filtro e fertilizante mineral provocaram aumento nos teores de $\mathrm{Zn}$ em relação ao tratamento controle; quanto ao $\mathrm{Cu}$, o teor presente no tratamento controle $\left(0,86 \mathrm{mg} \mathrm{dm}^{-3}\right)$ é considerado médio, segundo critérios estabelecidos por Alvarez et al. (1999); Cavalcanti et al. (2008) mas, quando houve aplicação da torta de filtro e fertilizante mineral, passaram a valores considerados altos (Cavalcanti et al., 2008); respostas similares aos teores de $\mathrm{Zn}$ e $\mathrm{Cu}$ foram obtidas para o Mn, para o qual a adição de doses crescentes de torta de filtro promoveu resposta linear no teor deste elemento no solo; além disto, este foi aumentado significativamente $(\mathrm{p}<0,01)$ em função da aplicação das fontes minerais porém em proporções menores (Tabela 6 ).

A torta de filtro alterou significativamente $(\mathrm{p}<0,01)$ os teores de matéria orgânica do solo $\left(\mathrm{g} \mathrm{kg}^{-1}\right)$. Este resultado corrobora com o trabalho desenvolvido por Korndörfer \& Anderson (1997), em que obtiveram incrementos no aporte de matéria orgânica após adição de torta de filtro ao solo; para a máxima dose de torta de filtro ( $37 \mathrm{~g} \mathrm{vaso}^{-1}$ ), os teores de matéria orgânica apresentaram aumentos de 69,9\% em relação à testemunha (Tabela 6); este aporte de material orgânico é de fundamental importância para os solos da região Nordeste que, naturalmente, apresentam baixos teores de matéria orgânica, o que coloca a torta de filtro como alternativa para elevação dos teores de matéria orgânica desses solos. Segundo Berton \& Valadares (1991), a elevação da concentração de matéria orgânica ao solo se constitui o principal benefício do uso agrícola de resíduos orgânicos em razão da sua contribuição para melhoria nas propriedades químicas, físicas e biológicas do solo.

\section{Teores de nutrientes em plantas de cana-de-açúcar}

Ocorreram respostas significativas $(\mathrm{p}<0,05)$ pelo teste $\mathrm{F}$ da interação entre adubação orgânica e mineral para todos os teores de nutrientes presentes na parte aérea da cana-de-açúcar (Tabela 7).

Os incrementos significativos nos teores de $\mathrm{N}$ do solo propiciados pela aplicação das doses crescentes de torta de filtro, não foram suficientes para alterar os teores de $\mathrm{N}\left(\mathrm{g} \mathrm{kg}^{-1}\right)$ presentes na parte aérea da cana-de-açúcar para os níveis 0 e $50 \%$ do fertilizante mineral), na qual não se constatou ajuste de modelos de regressão mas se obteve comportamento antagônico para o nível de $100 \%$, que se ajustou ao modelo quadrático (Tabela 8).

$\mathrm{Na}$ ausência da fonte mineral os teores de $\mathrm{N}$ variaram de 7,74 a $9,98 \mathrm{~g} \mathrm{~kg}^{-1}$; ao se utilizar $50 \%$ da adubação mineral observouse tendência de redução do teor de $\mathrm{N}$ da parte aérea, com teor máximo de $15,06 \mathrm{~g} \mathrm{~kg}^{-1}$; esta máxima concentração foi obtida na testemunha obtendo-se, também, comportamento similar para $100 \%$ da adubação mineral cujos teores máximos estavam presentes na testemunha. Os elevados teores foliares de $\mathrm{N}$ no tratamento controle se devem, basicamente, ao efeito de concentração na fitomassa tendo em vista que, neste caso, foram observadas as menores produtividades de material vegetal. 
Tabela 7. Análise de variância para os teores de macro e micronutrientes em plantas de cana-de-açúcar submetidas a doses crescentes de torta de filtro e fertilizante mineral

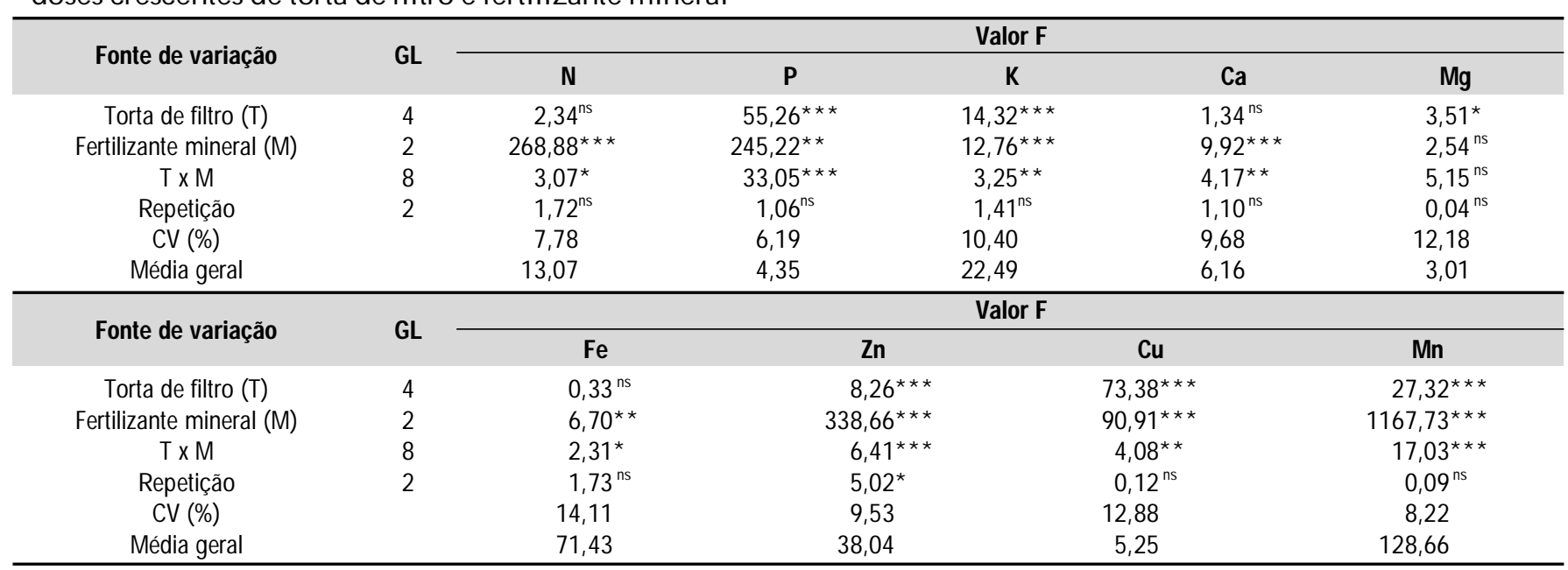

CV - coeficiente de variação; *, ** e *** - significativos a 5,1 e $0,1 \%$ de probabilidade, respectivamente; ns - não significativo

Tabela 8. Teores de macro e micronutrientes em plantas de cana-de-açúcar e respectivas equações de regressão, em função das doses de torta de filtro $\left(\mathrm{g} \mathrm{kg}^{-1}\right)$ nos diferentes níveis de fertilizante mineral

\begin{tabular}{|c|c|c|c|c|c|c|c|}
\hline \multirow{2}{*}{$\begin{array}{c}\text { Fertilizante } \\
\text { mineral }\end{array}$} & \multicolumn{5}{|c|}{ Torta de filtro $\left(\mathrm{g} \mathrm{kg}^{-1}\right)$} & \multirow{2}{*}{ Equação de regressão } & \multirow{2}{*}{$\mathbf{R}^{2}$} \\
\hline & 0 & 9,25 & 18,5 & 27,75 & 37 & & \\
\hline \multicolumn{8}{|c|}{$N\left(g_{k g}^{-1}\right)$} \\
\hline 0 & $7,71 \mathrm{c}$ & $7,23 c$ & $7,69 \mathrm{c}$ & $9,98 b$ & $8,72 b$ & $\hat{\mathrm{Y}}=\overline{\mathrm{Y}}=8,27$ & NS \\
\hline 50 & $15,06 b$ & $14,04 \mathrm{~b}$ & $14,36 b$ & $14,74 \mathrm{a}$ & $13,57 \mathrm{a}$ & $\hat{\mathrm{Y}}=\overline{\mathrm{Y}}=14,35$ & NS \\
\hline 100 & $18,33 \mathrm{a}$ & $16,98 \mathrm{a}$ & $16,51 \mathrm{a}$ & $15,86 \mathrm{a}$ & $16,58 \mathrm{a}$ & $\hat{Y}=18,45-0,17^{*} x+0,0033^{*} x^{2}$ & $0,96 *$ \\
\hline \multicolumn{8}{|c|}{$P\left(g_{~ k g}{ }^{-1}\right)$} \\
\hline 0 & $1,12 \mathrm{C}$ & $3,07 \mathrm{~b}$ & $3,96 \mathrm{~b}$ & $4,72 \mathrm{~b}$ & $5,42 \mathrm{a}$ & $\hat{Y}=1,6+0,11 x^{* *}$ & $0,95 * *$ \\
\hline 50 & $3,43 b$ & $3,54 b$ & $3,84 \mathrm{~b}$ & $4,19 b$ & $3,96 \mathrm{~b}$ & $\hat{Y}=3,11+0,018 x^{*}$ & $0,77^{*}$ \\
\hline 100 & $5,29 a$ & $5,87 a$ & $5,88 \mathrm{a}$ & 5,57 a & $5,41 \mathrm{a}$ & $\hat{Y}=5,3+0,38 x^{05 * *}-60,06 * * x$ & $0,96 *$ \\
\hline \multicolumn{8}{|c|}{$\mathrm{K}\left(\mathrm{g} \mathrm{kg}^{-1}\right)$} \\
\hline 0 & $17,95 \mathrm{a}$ & $14,31 \mathrm{c}$ & $18,41 b$ & $24,19 a$ & $27,33 a$ & $\hat{Y}=17,83-3,62^{*} x^{0,5}+0,87^{*} x$ & $0,97 *$ \\
\hline 50 & $19,43 a$ & $19,32 b$ & $24,51 \mathrm{a}$ & 24,62 a & $23,61 \mathrm{a}$ & $\hat{\mathrm{Y}}=\overline{\mathrm{Y}}=22,29$ & NS \\
\hline 100 & 21,82 a & $24,25 a$ & $25,15 a$ & 25,99 a & $26,49 a$ & $\hat{Y}=22,52+0,1199 * * x$ & $0,90 *$ \\
\hline \multicolumn{8}{|c|}{$\mathrm{Ca}\left(\mathrm{g} \mathrm{kg}^{-1}\right)$} \\
\hline 0 & $5,72 \mathrm{a}$ & 6,19 a & $5,48 \mathrm{a}$ & 6,05 a & $4,85 b$ & $\hat{\mathrm{Y}}=\overline{\mathrm{Y}}=5,65$ & NS \\
\hline 50 & $6,50 a$ & $6,30 \mathrm{a}$ & $6,56 a$ & 7,19 a & $6,57 a$ & $\hat{\mathrm{Y}}=\overline{\mathrm{Y}}=6,62$ & NS \\
\hline 100 & $5,38 a$ & $5,80 \mathrm{a}$ & $6,16 a$ & 6,06 a & $7,67 \mathrm{a}$ & $\hat{Y}=5,24+0,05^{*} x$ & $0,77^{*}$ \\
\hline \multicolumn{8}{|c|}{$\mathrm{Mg}\left(\mathrm{g} \mathrm{kg}^{-1}\right)$} \\
\hline 0 & $2,47 a$ & $3,69 a$ & $3,04 a$ & $3,57 \mathrm{a}$ & $2,59 b$ & $\hat{Y}=\bar{Y}=3,07$ & NS \\
\hline 50 & $3,14 a$ & $2,76 b$ & $2,95 \mathrm{a}$ & $3,27 a b$ & $3,52 \mathrm{a}$ & $\hat{\mathrm{Y}}=\overline{\mathrm{Y}}=3,12$ & NS \\
\hline 100 & $2,55 a$ & $2,68 b$ & $2,56 \mathrm{a}$ & $3,74 \mathrm{~b}$ & $3,68 \mathrm{a}$ & $\hat{Y}=\bar{Y}=2,84$ & NS \\
\hline \multicolumn{8}{|c|}{$\mathrm{Cu}\left(\mathrm{mg} \mathrm{kg}^{-1}\right)$} \\
\hline 0 & $1,13 b$ & $1,52 \mathrm{c}$ & $3,72 b$ & $5,13 b$ & $7,06 \mathrm{a}$ & $\hat{\mathrm{Y}}=0,62+0,16 * * x$ & $0,97^{* *}$ \\
\hline 50 & $2,18 b$ & $4,02 b$ & $4,68 \mathrm{~b}$ & $7,25 a$ & $7,03 a$ & $\hat{\mathrm{Y}}=2,44+0,14 * * x$ & $0,92 * *$ \\
\hline 100 & $5,50 a$ & $5,76 a$ & $7,43 a$ & $8,16 a$ & $8,25 \mathrm{a}$ & $\hat{\mathrm{Y}}=5,44+0,08 * * \mathrm{x}$ & $0,91 * *$ \\
\hline \multicolumn{8}{|c|}{$\mathrm{Fe}\left(\mathrm{mg} \mathrm{kg}^{-1}\right)$} \\
\hline 0 & $52,52 \mathrm{~b}$ & $79,28 \mathrm{a}$ & $71,77 \mathrm{a}$ & 64,65 a & $61,05 \mathrm{a}$ & $\hat{Y}=\bar{Y}=67,05$ & NS \\
\hline 50 & $66,71 a b$ & 62,35 a & $66,75 a$ & 75,61 a & $76,18 a b$ & $\hat{Y}=\bar{Y}=69,52$ & NS \\
\hline 100 & $85,47 a$ & 74,78 a & $78,48 \mathrm{a}$ & $73,28 \mathrm{a}$ & 82,55 a & $\hat{\mathrm{Y}}=\overline{\mathrm{Y}}=78,91$ & NS \\
\hline \multicolumn{8}{|c|}{$\mathrm{Zn}\left(\mathrm{mg} \mathrm{kg}^{-1}\right)$} \\
\hline 0 & $18,04 \mathrm{c}$ & $17,37 \mathrm{c}$ & $21,70 \mathrm{c}$ & $19,79 \mathrm{c}$ & $23,44 c$ & $\hat{Y}=\bar{Y}=20,01$ & NS \\
\hline 50 & $32,73 b$ & $40,96 \mathrm{~b}$ & $39,83 \mathrm{~b}$ & $37,01 b$ & $34,99 \mathrm{~b}$ & $\hat{\mathrm{Y}}=\overline{\mathrm{Y}}=37,10$ & NS \\
\hline 100 & $51,81 \mathrm{a}$ & $67,65 a$ & $51,94 \mathrm{a}$ & $48,58 \mathrm{a}$ & $64,86 \mathrm{a}$ & $\hat{\mathrm{Y}}=\overline{\mathrm{Y}}=56,96$ & NS \\
\hline \multicolumn{8}{|c|}{$\mathrm{Mn}\left(\mathrm{mg} \mathrm{kg}^{-1}\right)$} \\
\hline 0 & $27,07 \mathrm{c}$ & $20,08 \mathrm{c}$ & $24,71 \mathrm{c}$ & $28,44 \mathrm{c}$ & $36,79 \mathrm{c}$ & $\hat{Y}=27,1-6,09 * * x^{0,5}+1,25^{* *} x$ & $0,98 *$ \\
\hline 50 & $118,09 \mathrm{~b}$ & $176,51 b$ & $165,75 \mathrm{~b}$ & $160,16 \mathrm{~b}$ & $116,58 b$ & $\hat{Y}=117,45+39,33 * * x^{0,5}-6,32 * x$ & $0,94 * *$ \\
\hline 100 & 144,34 a & $220,81 \mathrm{a}$ & $218,88 a$ & $234,21 a$ & $237,52 \mathrm{a}$ & $\hat{Y}=145,41+29,97 * x^{0,5}-2,5^{n s} x$ & $0,97^{*}$ \\
\hline
\end{tabular}

Letras minúsculas e distintas na coluna diferem entre si pelo teste Tukey a $5 \%$ de probabilidade; ${ }^{*} \mathrm{e}^{* *}$ : significativos a $5 \%$ e $1 \%$ de probabilidade, respectivamente; ns: não significativo 
$\mathrm{Na}$ ausência da adubação mineral a torta de filtro promoveu incrementos significativos nos teores de $\mathrm{P}$ da parte aérea (mg $\left.\mathrm{kg}^{-1}\right)$, mostrando seu potencial como fertilizante fosfatado e comportamento similar para $\mathrm{AM}_{1}$ respondendo, de forma linear, à aplicação das doses crescentes de torta de filtro (Tabela 8); no entanto, para $\mathrm{AM}_{2}$ não foi verificada diferença significativa nos teores de $\mathrm{P}$ da parte aérea, situação devida, sem dúvida, aos altos teores de $\mathrm{P}$ do solo advindos do aporte orgânico e mineral. O teor de P presente no tecido foliar da testemunha $\left(1,12 \mathrm{~g} \mathrm{~kg}^{-1}\right)$ ficou abaixo da faixa considerada normal para a cultura (Malavolta et al., 1989; Raij \& Cantarela, 1996); este tratamento, entretanto, apresentou as menores produções de fitomassa apesar da primeira dose de torta de filtro $\left(3,01 \mathrm{~g} \mathrm{~kg}^{-1}\right)$ ter sido suficiente para atingir os valores adequados para essa cultura (Malavolta et al., 1989; Raij \& Cantarela, 1996), o que corrobora com seu efeito positivo como fornecedora de $\mathrm{P}$ disponível às plantas.

A adubação orgânica alterou significativamente $(\mathrm{p}<0,01)$ a concentração de K presente na parte aérea nos diferentes níveis de fertilizante mineral; os teores foliares de K estão acima da faixa adequada para a cultura, conforme critério de Raij \& Cantarela (1996), exceção $\mathrm{AO}_{1} \mathrm{AM}_{0}$, mas é interessante notar que essa concentração, mais baixa que o tratamento testemunha nas parcelas que receberam adição de torta de filtro, é resultado da maior produção de fitomassa de cana-de-açúcar em resposta à adição da torta de filtro, que acarretou em maior demanda na absorção desse nutriente do solo.

Quanto ao Ca, não houve ajuste nos modelos de regressão nos níveis de adubação mineral estudados, exceção ao teor de Ca da parte aérea na máxima dose da fonte mineral (Tabela 8). Os teores de Ca nas plantas de cana-de-açúcar, entretanto, estão dentro da faixa considerada adequada à cultura (Malavolta et al., 1989; Raij \& Cantarela, 1996). Quanto ao Mg, não se notou ajuste de modelos de regressão para os teores e conteúdos de Mg (Tabela 8) e, na ausência da adubação mineral, apesar de não ter ocorrido ajuste no modelo de regressão a primeira dose de torta de filtro triplicou o conteúdo de $\mathrm{Mg}$ em relação à testemunha.

Os teores de $\mathrm{Cu}$ presentes na parte aérea aumentaram linearmente em função das doses de torta de filtro e fertilizante mineral aplicados (Tabelas 8); na ausência da adubação mineral os teores de $\mathrm{Cu}$ variaram de 1,13 a 7,06 mg kg-1, diferindo estatisticamente dos demais níveis de fertilizante mineral (Tabelas 8). Segundo Raij \& Cantarela (1996), os teores adequados de $\mathrm{Cu}$ para cana-de-açúcar estão na faixa de 6 a 15 $\mathrm{mg} \mathrm{kg}^{-1}$, mostrando que na ausência da adubação mineral a máxima dose de torta de filtro seria suficiente para atender às exigências nutricionais de $\mathrm{Cu}$ das plantas; desta forma, o $\mathrm{Cu}$ advindo da decomposição da torta de filtro poderá ser uma alternativa no suprimento de $\mathrm{Cu}$ para algumas regiões do Brasil, especialmente nos solos dos tabuleiros Costeiros do Nordeste que, naturalmente, são solos pobres em micronutrientes.

Não se verificou ajuste dos modelos de regressão nos diferentes níveis de fertilizante mineral para os teores de Fe na parte aérea da cana-de-açúcar (Tabela 8); no entanto, os teores de Fe presentes na parte aérea apresentaram valores médios de 65,$85 ; 69,52$ e 78,91 $\mathrm{mg} \mathrm{kg}^{-1}$ para os níveis de 0,50 e $100 \%$ de fertilizante mineral, respectivamente; esses valores se encontram dentro da faixa dos teores adequados para canade-açúcar, propostos por Raij \& Cantarela (1996), exceção feita à testemunha $\left(52,52 \mathrm{mg} \mathrm{kg}^{-1}\right)$.

Os teores de $\mathrm{Zn}$ da biomassa vegetal não se ajustaram a nenhum modelo de regressão; todavia, responderam positivamente à aplicação dos fertilizantes minerais (Tabela 8); as concentrações de Zn não só variaram de 18,04 a 23,44; 32,73 a 40,96 e 48,58 a $67,65 \mathrm{mg} \mathrm{kg}^{-1}$ para $\mathrm{AM}_{0}, \mathrm{AM}_{1}$ e $\mathrm{AM}_{2}$, respectivamente, mas estão dentro da faixa adequada (10 a 50 $\mathrm{mg} \mathrm{kg}^{-1}$ ) de acordo com Raij \& Cantarela (1996).

Os teores médios de Mn na parte aérea foram 27,42; 147,42 e 215,15 para os níveis de 0, 50 e 100\% da adubação mineral, respectivamente; apesar do conteúdo de Mn no solo ter aumentado com a aplicação de torta de filtro, seus teores não foram suficientes para alterar os conteúdos de Mn na planta de cana-de-açúcar (Tabela 8).

\section{CONCLUSÕES}

1. A aplicação de torta de filtro promoveu melhoria na fertilidade do solo em virtude de aumentar seus teores de macro e micronutrientes e reduzir os teores de $\mathrm{Al}$ promovendo, desta forma, uma ação corretiva da acidez do solo enquanto os fertilizantes minerais promoveram a acidificação.

2. As plantas de cana-de-açúcar responderam favoravelmente à adubação com torta de filtro, a qual aumentou o acúmulo de fósforo, potássio e cobre na parte aérea das plantas.

3. Recomenda-se o uso de torta de filtro associada à adubação mineral, como maneira de maximizar o efeito sobre a produtividade e reduzir custos com fertilizantes minerais.

\section{LITERATURA CITADA}

Almeida, A. Composto de lixo urbano na composição química do solo e seus efeitos no desenvolvimento de mudas de maracujazeiro amarelo (Passiflora f. flavicarpal). Revista Biociência, v.9, p.7-15, 2003.

Almeida Júnior, A. B. Adubação orgânica em cana-de-açúcar: Efeitos no solo e na planta. Recife: UFRPE, 2010. 58p. Dissertação Mestrado

Alvarez V., W. H.; Novais, R. F.; Barros, N. F.; Cantarutti, R.B.; Lopes, A. S. Interpretação dos resultados das análises de solos. In: Ribeiro, A. C.; Guimarães, P. T. G.; Alvarez V., V.H., (ed). Recomenendações para uso de corretivos e fertilizantes em Minas Gerais - 5ª aproximação. Viçosa: CFSEMG, 1999. p.25-32.

Alves, W. 1.; Melo, W. J.; Ferreira, M. E. Efeito de composto de lixo urbano em um solo arenoso e em plantas de sorgo. Revista Brasileira de Ciência do Solo, v.23, p. 729-736, 1999.

Amaral, A. S. do; Spader, V.; Anghinoni, I.; Neurer, E. J. Resíduos vegetais na superfície do solo afetam a acidez do solo e eficiência do herbicida flumetsulam. Ciência Rural, v.30, p.789-794, 2000. 
Bastos, A. L.; Costa, J. P. V.; Silva, I. F.; Raposo, R. W. C.; Souto, J. S. Influência de doses de fósforo no fluxo difusivo em solos de Alagoas. Revista Brasileira de Engenharia Agrícola e Ambiental, v.12, p.136-142, 2008.

Berton, R. S.; Valadares, J. M. A. S. Potencial agrícola do composto de lixo urbano no estado de São Paulo. O Agronômico, v.4, p.87-93, 1991.

Cavalcanti, F. J. de A.; Lima Júnior, M. A.; Lima, J. F. W. F. Recomendações de adubação para o estado de Pernambuco: $2^{\mathrm{a}}$ aproximação. 3 ed. Recife: Instituto Agronômico de Pernambuco- IPA, 2008. 212p.

Cortez, L; Magalhães, P.; Happ, J. Principais subprodutos da agroindústria canavieira e sua valorização. Revista Brasileira de Energia, v.2, p.111-146, 1992.

Costa, F.; Hernandez, T.; Garcia, C.; Ayuso, M.; Pascual, J.A. ; Apolo, A. Efecto residual de diferentes residuos orgánicos sobre um cultivo de cebada. Suelo Planta, v.2, p.593-603, 1992.

Cunha, G. de M.; Gama-Rodrigues, A. C.; Costa, G.S.; Velloso, A. C. X. Fósforo orgânico em solos sob florestas montanas, pastagens e eucalipto no norte fluminense. Revista Brasileira de Ciência do solo, v.31, p.667-672, 2007.

Donzelli, J. L.; Penatti, C. P. Manejo do solo classificado como Latossolo Roxo Acrico. Piracicaba: Centro de Tecnologia Copersucar, 1997, 8p. Relatório Técnico

EMBRAPA - Empresa Brasileira de Pesquisa Agropecuária. Manual de métodos de análises de solo. 2. ed. Rio de Janeiro: Centro Nacional de Pesquisa de Solos, 1997. 212 p.

EMBRAPA - Empresa Brasileira de Pesquisa Agropecuária. Manual de análises químicas de solos, plantas e fertilizantes. Brasília: EMBRAPA, 1999.370p.

Fravet, P. R. F. de; Soares, R. A. B.; Lana, R. M. Q.; Lana, A. M. Q.; Korndörfer, G. H. Efeito de doses de torta de filtro e modo de aplicação sobre a produtividade e qualidade tecnológica da soqueira de cana-de-açúcar. Ciência e Agrotecnologia, v.34, p.618-624, 2010.

Korndörfer, G. H.; Anderson, D. L. Use and impact of sugaralcohol residues vinasse and filter on sugarcane production in Brazil. Sugar y azucar, Engleood Cliffs, v.3, p.26-35, 1997.

Korndörfer, G. H.; Melo, S. P. Fontes de fósforo (fluida ou sólida) na produtividade agrícola e industrial da cana-de-açúcar. Ciência e Agrotecnologia, v.33, p.92-97, 2009.

Lima, R. de L. S. de; Fernandes, V. L. B.; Oliveira, V. H. de; Hernandez, F. F. F. Crescimento de mudas de cajueiro-anãoprecoce ' CCP-76' submetidas à adubação orgânica e mineral. Revista Brasileira de Fruticultura, v.23, p.391-395, 2001.

Malavolta, E.; Vitti, G. C.; Oliveira, S. A. de. Avaliação do estado nutricional das plantas. Piracicaba: Associação Brasileira para pesquisa da Potassa e do fosfato, 1989. 201p.

Matsuoka, S.; Margarido, L. A. C.; Lavorenti, N. A.; Elias Júnior, R.; Pinell, D. M. Comportamento de variedades de cana-deaçúcar em um sistema orgânico de produção. In: Congresso Nacional da STAB, 8, 2002, Recife. Anais... Recife: 2002, p.301-308.

Mazur, N.; Santos, G. A.; Velloso, A. C. X. Efeito do composto de resíduo urbano na disponibilidade de fósforo em solo ácido. Revista Brasileira de Ciência do Solo, v. 7, p.153-156, 1983.
Mendonça, E. S.; Rowell, D. L.; Martins, A. G.; Silva, A, P. Effect of $\mathrm{pH}$ on the development of acidic sites in clayey and Sandy loam Oxisol from the Cerrado Region, Brazil. Geoderma, v.132, p.131-142, 2006.

Mieyazawa, M.; Pavan, M. A.; Calegari, A. Efeito de material vegetal na acidez do solo. Revista Brasileira de Ciência do. Solo, v.17, p.411- 416, 1993.

Nardin, R. R. Torta de filtro aplicada em Argissolo e seus efeitos agronômicos em duas variedades de cana-de-açúcar colhidas em duas épocas. Campinas: Instituto Agronômico, 2007. 39p. Dissertação Mestrado

Nascimento, C. W. A.; Amarasiriwardena, D.; Xing, B. Comparison of natural organic acids and synthetic chelates at enhancing phytoextraction of metals from a multi-metal contaminated soil. Environmental Pollution (Barking), Massachusetts, v.140, p.114-123, 2006.

Nunes Júnior, D. Torta de filtro: De resíduo a produto nobre. Revista Idea News, n.92, p.22-30, 2008.

Oliveira, A. B. de.; Nascimento, C.W.A. Formas de manganês e ferro em solos de referência de Pernambuco. Revista Brasileira de Ciência do Solo, v.30, p.99-110, 2006.

Oliveira, V. A.; Lunkes, J. A.; Argenta J. A.; Oliveira, J. A.; Dias D. R. Efeito da adubação mineral e orgânica sobre a produção de biomassa e óleo essencial de capim-limão. Pro Homine, v.1, p.24-27, 2002.

Perin, E.; Ceretta, C. A.; Klamt, E. Tempo de uso agrícola e propriedades químicas de dois latossolos do planalto médio do Rio Grande do Sul. Revista Brasileira de Ciências do Solo, v.27, p.665-674, 2003.

Primavesi, A. C.; Primavesi, O.; Corrêa, L. A.; Cantarella, H.; Silva, A.G. Absorção de cátions e ânions pelo capimCoastcross adubado com uréia e nitrato de amônio. Pesquisa Agropecuária Brasileira, v.40, p.247-253, 2005.

Purquerio, L. F. V.; Cecílio Filho, A. B. Concentração de nitrogênio na solução nutritiva e número de frutos sobre a qualidade de frutos de melão. Horticultura Brasileira, v.2, p.831-836, 2005.

Raij, B. van; Cantarella, H. Outras culturas industriais. In: Raij, B. van; C. H.; Quaggio, J. A.; Furlani, A. M. C. (coord.) Recomendações de adubação e calagem para o Estado de São Paulo. 2.ed. Campinas: Instituto Agronômico e Fundação IAC, 1996. p.233-236.

Ribeiro, A. C.; Guimarães, P. T. G.; Alvarez, V. H. Recomendações para uso de corretivos e fertilizantes em Minas Gerais: $5^{\text {a }}$ aproximação. Minas Gerais: Comissão de Fertilidade do Solo do Estado de Minas Gerais, 1999. 359p.

Rossetto, R.; Dias, F. L. F.; Vitti, A. C. Problemas nutricionais dos solos nas novas fronteiras canavieiras. Revista Idea News, v.8, p.78-90, 2008.

Santos, D. H.; Silva, M. de A.; Tiritan, C. S.; Foloni, J. S. S.; Echer, F. R. Qualidade tecnológica da cana-de-açúcar sob adubação com torta de filtro enriquecida com fosfato solúvel. Revista Brasileira de Engenharia Agrícola e Ambiental, v.15, p.443-449, 2011.

Santos, D. H.; Tiritan, C. S.; Foloni, J. S. S.; Fabris, L. B. Produtividade de cana-de-açúcar sob adubação com torta de filtro enriquecida com fosfato solúvel. Pesquisa Agropecuária Tropical, v.40, p.454-461, 2010. 
Silva, M. S. L. da; Ribeiro, M. R. Influência do cultivo contínuo da cana-de-açúcar nas propriedades químicas dos solos argilosos. Pesquisa Agropecuária Brasileira, v.30, p.389-394, 1995.

Simas, F. N. B.; Schaefer, C.E. G R.; Fernandes-Filho, E. I.; Chagas, A. C.; Brandão, P. C. Chemistry, mineralogy and micropedology of highland soils on crystalline rocks of Serra da Mantiqueira, Southeastern Brazil. Geoderma, v.125, p.187-201, 2005.

Sousa, R. A de.; Silva, T. R. B. de. A acidificação de um Latossolo Vermelho Distroférrico em função da aplicação de nitrogênio oriundo de uréia, sulfato de amônio e sulfammo. Cultivando o Saber, v.2, p.78-83, 2009.

Souza, T. R.; Quaggio, J. A.; Silva, G. O. Dinâmica de íons e acidificação do solo nos sistemas de fertirrigação e adubação sólida na citricultura. Revista Brasileira de Fruticultura, v.28, p.501-505, 2006.
Tedesco, M. J. Análise de solo, plantas e outros minerais. 2 ed. Porto Alegre: UFRGS, Departamento de Solos, 1995. $174 \mathrm{p}$.

Teixeira, L. A. J.; Natale, W.; Ruggiero, C. Alterações em alguns atributos químicos do solo decorrentes da irrigação e adubação nitrogenada e potássica em bananeira após dois ciclos de cultivo. Revista Brasileira de Fruticultura, v.23, p.684-689, 2001.

van Hees, P. A.W.; Lundstrom, U. S.; Starr, M.; Giesler, R. Factores influencing aluminium concentrations in soil solution from podzols. Geoderma, v.94, p.289-310, 2000.

Vitti, G. C; Mazza, J. A. Planejamento, estratégias de manejo e nutrição de cana-de-açúcar. Informações Agronômicas, n.97, p. 1-16, 2002. 